- Bacteria must be eliminated from the root canal system prior to obturation for endodontic treatment to be successful.

- Sodium hypochlorite solution is the most effective endodontic irrigant in current usage, but it is not effective against all the bacteria found in the root canal system.

- Photo-Activated Disinfection (PAD) offers the potential to effectively kill endodontic bacteria with fewer toxic effects and more quickly than with sodium hypochlorite solution.

\title{
An alternative regimen for root canal disinfection
}

\author{
S. J. Bonsor, ${ }^{1}$ R. Nichol, ${ }^{2}$ T. M. S. Reid ${ }^{3}$ and G. J. Pearson ${ }^{4}$
}

Objective To compare the effect of a combination of $20 \%$ citric acid solution and photo-activated disinfection with the use of $20 \%$ citric acid and $2.25 \%$ sodium hypochlorite solutions on bacterial load on the dentine walls in prepared canals in vivo.

Subjects and methods Sixty-four randomly selected cases were evaluated and allocated to one of two groups. In Group 1, after gaining access to the root canal, bacterial load on the canal walls was sampled using endodontic files. A further sample was taken after apex location and initial widening of the canal had been completed and the photoactivated disinfection process carried out. A final sample was taken after completion of the canal preparation using citric acid and sodium hypochlorite solutions. In Group 2, the initial sample was taken as described previously. A second sample was taken after conventional preparation using 20\% citric acid and sodium hypochlorite solutions as co-irrigants. A final sample was then taken after a subsequent PAD treatment. All samples were cultured for facultative anaerobic bacteria. Results Of the canals treated in Group 1 only two of the 23 canals infected showed culturable bacteria after the use of citric acid and photo-activated disinfection. Of these two canals, one was free of culturable bacteria on completion of conventional treatment but the other still contained culturable bacteria. In Group 2, four canals of the 23 infected initially, remained contaminated after conventional treatment. After subsequent photo-activated disinfection three of these four canals were free of culturable bacteria.

Conclusion Results indicate that the use of a chelating agent acting as a cleaner and disrupter of the biofilm and photo-activated disinfection to kill bacteria is an effective alternative to the use of hypochlorite as a root canal cleaning system.

\footnotetext{
${ }^{1 *}$ General Dental Practitioner, The Dental Practice, 21 Rubislaw Terrace, Aberdeen AB10

$1 X E_{;}^{2,3}$, Department of Medical Microbiology, NHS Grampian, Aberdeen AB25 2ZN; ${ }^{4}$, Department of Biomaterials in Relation to Dentistry, Barts and London School of Medicine and Dentistry, Queen Mary University of London E1 4NS

${ }^{*}$ Correspondence to: Dr Stephen Bonsor

Email: steve.b@thedentalpracticeaberdeen.co.uk
}

\section{INTRODUCTION}

In the preparation of a root canal both the efficient instrumentation to shape and the effective cleaning and disinfecting of the walls and lumen of the canal are essential for a successful outcome to treatment. ${ }^{1}$ It is widely recognised that residual bacterial contamination of the canals is likely to lead to failure. ${ }^{2-4}$ Therefore bacteria remaining within a canal after chemo-mechanical preparation must be reduced to a minimum for successful treatment.

It is generally accepted that the effective elimination of bacteria requires the initial cleaning of the canal by removal of the smear layer ${ }^{5,6}$ and the subsequent break up of the biofilm leaving the bacteria accessible to the disinfecting agent. There are a range of materials which will remove the smear and/or disturb the biofilm structure. These include sodium hypochlorite, EDTA, citric acid and polyacrylic acid. ${ }^{7-12}$ of the irrigants used, sodium hypochlorite is currently preferred by most clinicians as it exhibits a proteolytic effect as well as being a disinfectant.

However, for its bactericidal effect, sodium hypochlorite relies heavily on the duration of time retained in the canal and the use of copious volumes of the solution since it is the free chlorine which acts as the disinfecting agent and this is used up rapidly. It has been shown that 20-30 minutes is required to clean and debride a canal. ${ }^{13}$ A small volume used for a short contact time will have a limited effect. Furthermore, there is evidence that hypochlorite is not effective against all pathogenic bacteria specifically Enterococcus faecalis which is associated with recalcitrant canals. ${ }^{14}$

Further complications of conventional disinfecting agents are toxicity and microbial resistance ${ }^{15-17}$ since most which have effective bactericidal activity are used at concentrations where normal tissue toxicity is becoming a significant factor. This can lead to adverse tissue reactions.

Despite sodium hypochlorite being regarded as the irrigant of choice, the substantial dwell time for effective elimination of bacteria and the risk of swelling and haematoma formation if extruded into the soft tissue beyond the apex are potential disadvantages which has been reported in a number of cases. ${ }^{18,19}$ Furthermore, at the concentrations recommended, its bactericidal level and tissue damage level are relatively close together. ${ }^{7,8}$

Additionally, the more concentrated the solution, its surface 
tension increases leading to the solution not wetting the surface of the walls of the canal well. ${ }^{20-22}$ This potentially leads to inadequate disruption of any biofilm layer present on the surface of the canal wall and limits penetration of the solution into the lateral canals or dentinal tubules. Recently a novel disinfecting system has been tested as an adjunct to conventional root canal therapy using sodium hypochlorite and citric acid as root canal cleaners. ${ }^{23}$

The PAD process uses a photosensitiser, specifically Tolonium chloride solution (TC) (a pharmaceutical grade of Toluidine Blue 0 ), and light of a specific wavelength [633 $\pm 2 \mathrm{~nm}]$. This may be used in conjunction with a biofilm/smear remover such as citric acid.

Addition of TC followed by irradiation with light has been shown to kill high numbers of bacteria in planktonic suspension, in collagen and carious dentine, ${ }^{24,25}$ and in root canals in vitro, ${ }^{26}$ probably by disruption of the cell membrane by short range free radicals or reactive oxygen species. ${ }^{27}$ The object of the current study was to evaluate the effect of using the novel disinfection system earlier in the treatment procedure and to compare this with the bacterial load after conventional endodontic preparation of the canals using hypochlorite by measuring the bacterial load at these points in the procedure.

\section{MATERIALS AND METHOD}

\section{Clinical procedure}

The trial was carried out in a private general dental practice in Scotland by the same operator. Ethical approval having been obtained, patients were selected at random. They were in good general health and between the ages of 16 and 70. Pregnant or nursing females and patients undergoing systemic photodynamic therapy (PDT) were excluded from the trial. The patients presented with symptoms of irreversible pulpitis or periradicular periodontitis either as a clinical diagnosis or evidence of radiographic change. They all required root canal therapy on teeth with closed apices. Informed written consent was obtained and each patient was then allocated to one of two groups. Sixty-four canals were treated in total. The distribution of teeth within each group was similar, 73\% in group 1 and 76\% in Group 2 being molars. The remainder in each group were single rooted teeth. In all cases, a pre-operative periapical radiograph was taken in a double film pack (Kodak, UK) using a long cone technique with an EndoRay film holder (Rinn Corporation, USA) to determine approximate canal length and canal morphology. After local anaesthetic had been administered, isolation with rubber dam was achieved and this was sealed with OraSeal Caulking (Ultradent Products Inc, USA.) In order to ensure the crown of the tooth was bacteria free, it and the surrounding dam were irrigated with PAD solution provided by the manufacturer (Tolonium chloride, Denfotex Ltd, Inverkeithing, UK.) The crown was then irradiated with a SaveDent light (Denfotex Ltd, Inverkeithing, UK) for 60 seconds at $100 \mathrm{~mW}$. The emitter tip was held in close proximity to the crown of the tooth and moved around the crown circumference with at least two rotations being completed in the first thirty seconds. The remaining 30 seconds were used to irradiate the area surrounding the access cavity. Laboratory studies have shown that this type of treatment effectively kills bacteria in a biofilm. ${ }^{26,28}$

In all cases, access to the pulp chamber was gained. Once the canals had been identified, accessed and canal patency ascertained, a size 15.02 sterile nickel-titanium hand file (Dentsply Maillefer, Ballaigues, Switzerland) was placed within the lumen of the canal at a point where resistance to the instrument's progress was just felt. It was filed backwards to remove debris from the canal walls and this instrument together with the swarf sample (dentine debris) obtained was placed in a sterile bottle as described previously. ${ }^{23}$ Great care was taken in multi-rooted teeth to ensure that no cross contamination occurred between the canals during the sampling process as each canal was regarded as a test unit. The initial sample was transported immediately to the Medical Microbiology Department at the local general hospital (Aberdeen Royal Infirmary, Grampian University Hospitals Trust) for culturing. This was identified either as sample X in Group 1 or Sample A in Group 2. Thirty-two canals were evaluated in both Groups 1 and 2.

\section{Group 1}

In Group 1, once the canal working length had been determined using an apex locator (AFA Analytic, Kerr Corporation, USA), the coronal aspect of the canal was prepared using ProTapers (Dentsply Maillefer) using a crown down approach working to $2 \mathrm{~mm}$ short of the working length. These instruments were of similar design to GT Rotaries used elsewhere. This permitted the endodontic emitter fibre from the SaveDent laser to be placed down the canal with the tip within $4 \mathrm{~mm}$ of the working length. The flexible emitter tip produces a uniform $15 \mathrm{~mm}$ long cylinder of light enabling all parts of the root canal to be irradiated from within. Copious irrigation (more than $20 \mathrm{ml}$ of each irrigant per canal) was used between instrumentations alternating between 20\% Citric Acid solution (Western Infirmary Glasgow, UK) and sterile water (Baxters, UK). The irrigants were injected down the canal using a sterile (gauge 27) endodontic micro-needle (Monoject, Tyco Healthcare, Gosport, UK)

The canal was then washed thoroughly with sterile water to remove any citric acid solution and dried with sterile paper points (Dentsply, DeTrey, Konstanz, Germany).

The photosensitiser solution (TC) was introduced into the canal using an endodontic micro-needle. The liquid was agitated in each canal for 60 seconds using a size 25.02 nickel-titanium hand file to ensure that the fluid passed to the working length and that any trapped air introduced into the canal was removed. The endodontic emitter was then inserted until it was within $4 \mathrm{~mm}$ of the measured working length. Light was then delivered at $100 \mathrm{~mW}$ for a period of 120 seconds in each canal (an energy dose of 12 Joules). Following withdrawal of the emitter, a new sterile size 35.02 nickel-titanium hand file was inserted to the working length and a further sample of swarf was obtained in the same manner from the full length of the canal. This was transferred to a fresh sterile bottle (Sample Y). At no stage prior to this was sodium hypochlorite used to irrigate the canal.

Profiles .04 (Dentsply Maillefer) were then used to prepare the apical two millimetres of the canal to completion. Copious irrigation was used between instrumentations (again more than $20 \mathrm{ml}$ of each irrigant per canal) alternating between $20 \%$ citric acid solution and 2.25\% sodium hypochlorite solution (4.5\% commercial thin bleach (Tesco, UK) diluted 50:50 with water.) All irrigants were used at ambient temperature. The canal wall was then sampled as before using a .02 nickel-titanium hand file one size larger than the master apical file (MAF.) This file with the swarf sampled was deposited in a fresh sterile bottle (Sample Z.) Samples $\mathrm{Y}$ and $\mathrm{Z}$ were transported immediately to the Microbiology Department for culturing. The maximum time between collecting the samples and plating in the microbiological laboratory was 30 minutes.

Each canal was finally flushed with sodium hypochlorite solution and dried with sterile paper points. A non-setting calcium hydroxide paste (UltraCal, Ultradent Products, USA) was placed into the canal, a cotton wool pledget (Roeko, Langenau, Germany) placed in the pulp chamber and the tooth was dressed with either IRM (Dentsply, DeTrey) in the case of posterior teeth or Chemfil Superior (Dentsply, DeTrey) in the case of anterior teeth.

At a subsequent visit, each canal was sealed using conventional techniques and formed a cohort of teeth for review at a later stage. 


\section{Group 2}

In Group 2, after the canal working length had been determined as described above, the canals were prepared in a similar fashion using GT Rotaries working to $2 \mathrm{~mm}$ short of the working length. Profiles .04 were then used to prepare the apical two millimetres. Copious irrigation (more than $20 \mathrm{ml}$ of each irrigant per canal) was used between instrumentations alternating between 20\% Citric Acid solution and 2.25\% sodium hypochlorite solution using the same irrigation techniques as described previously.

The canal was then washed thoroughly with sterile water to remove any residual irrigant and then sampled as before using a .02 nickel-titanium hand file one size larger than the master apical file. This file with the dentine sample was deposited in a fresh sterile bottle (Sample B) and the canal dried with sterile paper points. At this stage the canal was considered to be prepared and ready for obturation.

The TC solution was then injected into the canal using a sterile endodontic micro-needle (gauge 27) ensuring that the fluid passed to the working length. The liquid was agitated in each canal for 60 seconds using a .02 nickel-titanium hand file, two sizes smaller than the master apical file (MAF.) The endodontic emitter was then inserted into each canal until it was within $4 \mathrm{~mm}$ of the measured working length. Light was then delivered at $100 \mathrm{~mW}$ for a period of 120 seconds (an energy dose of 12 Joules). The emitter was moved up and down about $3 \mathrm{~mm}$ at 20 second intervals during the irradiation time.

Following withdrawal of the emitter, a new sterile .02 nickeltitanium hand file two sizes larger than the MAF was inserted and a further sample of swarf from the canal wall was obtained in the same manner. This was transferred to a fresh sterile bottle (Sample C) and the canals dried with sterile paper points. Samples B and C were again transported immediately to the Microbiology Department for culturing. The teeth were then dressed as described above for Group 1. At a subsequent visit, each canal was sealed using conventional techniques and formed a cohort of teeth for review at a later stage.

\section{Microbial assessment of swarf samples}

The objective of the assay was to assess the microbial load of facultative anaerobes at the various sampling times during the treatment. Facultative anaerobes were chosen because they are the predominant organisms in the human mouth, and are frequently implicated in infected dental root canals. Furthermore even with the most stringent anaerobic isolation techniques with prereduced media, it is often impossible to grow strict anaerobes. Root canal infections are polymicrobial, and strict anaerobes can only grow once facultative anaerobic organisms have lowered the redox potential of the local environment. The culture media was selected to facilitate the culture of common endodontic bacterial pathogens. No attempt was made to identify specific species.

On arrival at the microbiological facility, a sterile swab was moistened with sterile nutrient broth (Oxoid Code CM1) and excess fluid expressed. This swab was used to collect the swarf from the full cutting length of the file and rolled onto a fresh blood Agar plate (Oxoid Columbia Blood Agar base + 5\% sterile horse blood.) A sterile loop was used to streak five lines from the well. This streak pattern was repeated a further three times giving five growth areas in total (the well area plus the four streaked areas). This ensured standardisation of plating (Fig. 1). The plates were incubated in a Don Whitley Anaerobic Workstation in an atmosphere of $1 \%$ hydrogen, 10\% carbon dioxide and 80\% nitrogen. The use of a palladium catalyst ensured that the oxygen level was less than $1 \%$ within 20 minutes and less than 0.55\% within three hours. They were then examined and scored. If growth occurred in the well area, a score of one was allocated. If the growth occurred in both the well and the first five streaked lines, this was scored two and so on up to a maximum score of five. The greater the extent of growth observed then the greater bacterial load present.

To provide a semi-quantitative method of evaluating the numbers of bacteria involved, a culture was carried out by inoculating a known concentration of oral streptococci in similar fashion. This was carried out using National Committee for Clinical Laboratory Standards Methods (Clinical and Laboratory Standards Institute, Wayne, PA, USA). A streptococcal strain was selected as being representative of the most common organisms involved and an inoculum prepared using a colorimeter (Biomerieux Ltd). A suspension was made in saline and adjusted using the instrument to a 0.5 McFarland standard. This equates to the level of $1.5 \times 10^{8}$ colony forming units. A sterile endodontic file was placed in the suspension, allowed to drain, swabbed and inoculated onto the agar. Plating out in the described manner showed this growth to give a score of two. All cultures were performed in triplicate.

\section{RESULTS}

The distribution of bacterial load scores for the culture taken at the times indicated in the procedure is set out in Table 1 and 2. Of the initial cultures immediately after accessing the canal, (Samples A and X,) the scores ranged from four to zero. In Group 1 , nine of the 32 teeth showed an initial score of zero; in Group 2 a similar number were uncontaminated. These canals initially uninfected were excluded from the study. In both groups there remained 23 canals with initial bacterial load. In Group 1, after the earlier PAD treatment, all of the canal wall cultures (Sample

\begin{tabular}{|c|c|c|c|}
\hline $\begin{array}{l}\text { Score } \\
\text { Bacterial Load }\end{array}$ & Sample X & Sample Y & Sample Z \\
\hline 0 & 0 & 21 & 22 \\
\hline 1 & 12 & 1 & 1 \\
\hline 2 & 6 & 1 & 0 \\
\hline 3 & 3 & 0 & 0 \\
\hline 4 & 2 & 0 & 0 \\
\hline 5 & 0 & 0 & 0 \\
\hline $\begin{array}{l}\text { Total } \\
\text { infected canals }\end{array}$ & 23 & 2 & 1 \\
\hline
\end{tabular}

Table 2 Bacterial load scores per canal for each sample time in Group II excluding initially uninfected canals. Sample A = at access, Sample B = after conventional treatment, Sample $C=$ after PAD treatment.

\begin{tabular}{c|c|c|c}
\hline $\begin{array}{l}\text { Score } \\
\text { Bacterial Load }\end{array}$ & Sample A & Sample B & Sample C \\
\hline 0 & 0 & 17 & 20 \\
\hline 1 & 7 & 3 & 1 \\
\hline 2 & 8 & 1 & 0 \\
\hline 3 & 7 & 0 & 0 \\
\hline 4 & 1 & 0 & 0 \\
\hline 5 & 0 & 0 & $\mathbf{1 / 2 1 *}$ \\
\hline $\begin{array}{l}\text { Total } \\
\text { infected canals }\end{array}$ & $\mathbf{2 3}$ & $\mathbf{4 / 2 1 *}$ & 0 \\
\hline *In two cases Samples B and Carrived outside the time limit and the results were excluded
\end{tabular}




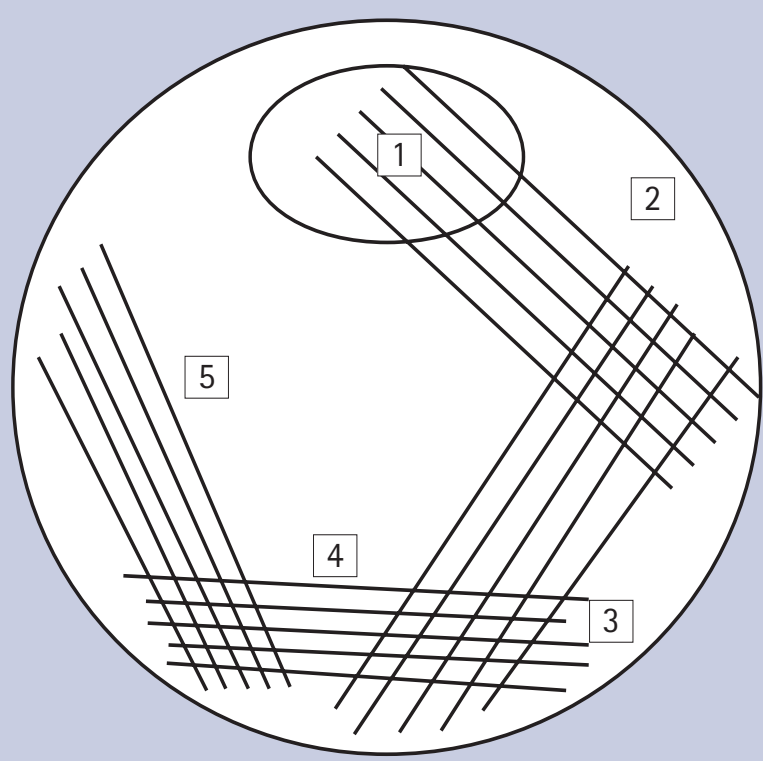

Fig. 1 Diagrammatic representation of plating of microbial growth. Numbers indicate sequence of streaking the culture: 2 equivalent to a total of $1.5 \times 108$ bacteria

Table 3 Stastical analysis of scores using ${ }^{2}$

\begin{tabular}{l|c|c|c}
\hline Initial load & $X$ & & \\
\hline $\begin{array}{l}\text { After } \\
\text { conventional }\end{array}$ & HS & $X$ & \\
\hline After PAD & HS & NS & $X$ \\
\hline & Initial Load & $\begin{array}{l}\text { After } \\
\text { conventional }\end{array}$ & After PAD \\
\hline HS = Highly significant NS = Not significant &
\end{tabular}

Y) except for two had a score of zero (Fig. 2). After the completion of the endodontic preparation, the cultures taken from the walls of the canal in these remaining two canals scored one and zero. In Group 2, after hypochlorite and citric acid treatment on completion of the conventional treatment, four of the canals contained culturable material (Fig. 3). The subsequent use of the PAD treatment eliminated all culturable bacteria in three of the four canals. In the fourth canal it was found that the emitter failed to deliver the correct energy dose as the tip had become damaged and confirmed in the laboratory subsequently. A comparative statistical analysis of the two treatment modalities comparing canals with culturable bacteria with those with no culturable material using ${ }^{2}$ showed that there was a highly significant reduction in bacterial load with each treatment modality between samples $\mathrm{X}$ and $\mathrm{Y}$ and between samples $\mathrm{A}$ and B. The level of reduction of load after Y and B were not significantly different.

\section{DISCUSSION}

While sodium hypochlorite is regarded by most as the solution of choice for irrigating canals, there are concerns as to the ability of the sodium hypochlorite to wet the canal walls adequately and disrupt the biofilm. The time taken and volume of the irrigant required for effective disinfection also prolongs the treatment time. The combination of citric acid as a cleaning agent to remove smear and break up the biofilm followed by subsequent use of photo-activated disinfection has therefore been assessed as an alternative to conventional continuous irrigation with sodium hypochlorite solution. This follows previous

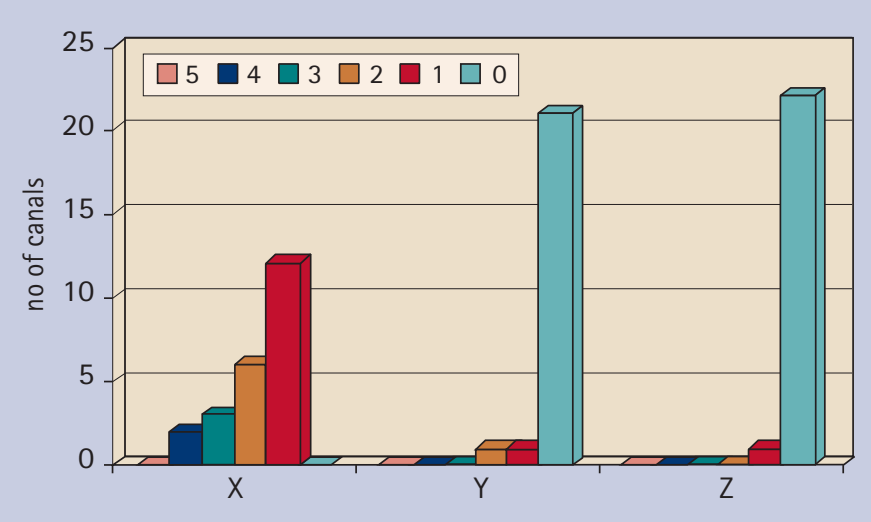

Fig. 2 Bar chart showing numbers of canals with bacterial loads at each sampling time for early exposure to PAD after exclusion of initial negative cultures

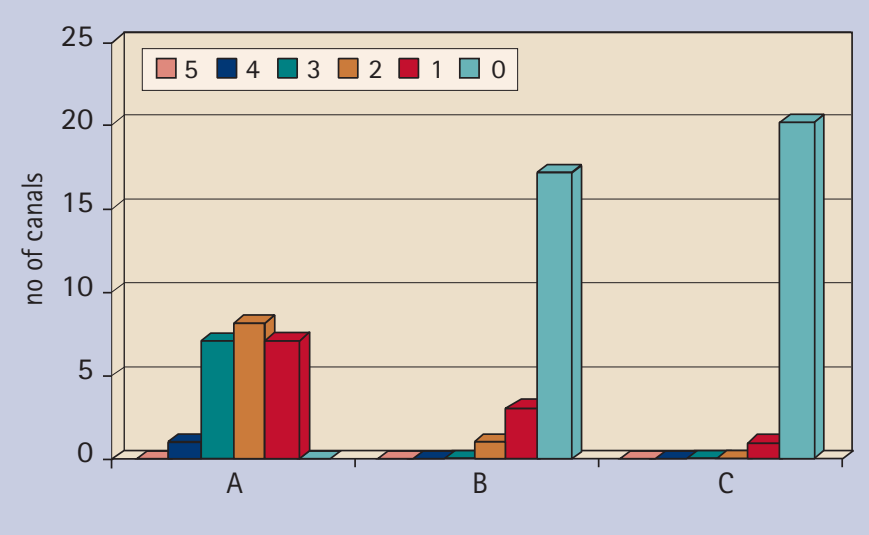

Fig. 3 Bar chart showing numbers of canals with bacterial load at each sampling time for conventional hypochlorite treatments after exclusion of initial negative cultures

work in which it was established that the use of hypochlorite was successful in eliminating culturable bacteria from the walls of the canals in only 76\% of the cases treated. ${ }^{23}$ Citric acid is a well documented chelating agent and had been used frequently in dentistry as a means of smear removal and breakdown of any biofilm layer. Its use, prior to a disinfecting agent, as a biofilm disrupter would facilitate the passage of the disinfecting solution into both the lateral canals and open dentinal tubules. ${ }^{29}$ Citric acid is well accepted biologically and at the concentration used here would not have any deleterious action on the surrounding tissue as it is not highly ionised. Once the root canal surface has been cleaned the spread of the disinfectant solution is dependent on the viscosity and surface tension of the solution used. The aqueous solution of the photosensitiser has good wettability properties and Stringer et al. ${ }^{30}$ have demonstrated the

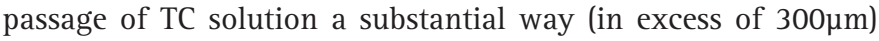
into dentine slices in vitro. Similarly the light/photosensitiser technique has been shown not to have a deleterious effect on the surrounding tissue. ${ }^{31,32}$

In Group 1, after the crown down procedure, use of the citric acid/PAD process has successfully reduced the bacterial load in all but two cases (91\%). The effect of this combination procedure would appear to be effective debridement being achieved in the crown down procedure permitting penetration of the canal walls by the disinfecting solution. The activation of the disinfecting system then reduces the bacterial load.

Light transmission through the tooth tissue at the operating wavelength appears to be good and attenuation in sound dentine ${ }^{33}$ is minimal with up to $3 \mathrm{~mm}$ thick dentine slices. 
In Group 1 there was one case which still showed a bacterial load after use of both PAD and sodium hypochlorite solution. There had been a considerable reduction in bacterial load after PAD but there was no further effect thereafter. The tooth involved was an upper central incisor, with a wide canal. The failure to eliminate the bacteria at first pass was surprising since the anatomy of this canal was relatively simple. Here however, the radiograph of the precementation master point shows that the apex had been breached and it appeared likely the samples included periapical material which would not have been treated by the PAD nor hypochlorite solution. No attempt was made to introduce the irrigating solutions beyond the apex and therefore their influence would have been negligible. In the other case where bacterial load remained after the PAD process, it had been reduced substantially and the further use of conventional irrigating solutions achieved a canal free of culturable bacteria by the end of preparation.

The 93\% of the cases in Group 1 which were free of culturable bacteria after the crown down procedure was considered to be complete was better than that achieved in Group 2 where the conventional techniques achieved only a $76 \%$ success rate using conventional chemo-mechanical methods.

The alternative technique described here indicates that it would be possible to disinfect the root canal system without the use of sodium hypochlorite. PAD has been shown to be as effective as conventional chemo-mechanical techniques but is more biocompatible and could potentially decrease the time spent disinfecting the root canal system.

\section{CONCLUSIONS}

Within the limits of the current study, the use of an alternative means of root canal disinfection to sodium hypochlorite has been shown to be more effective at reducing or eliminating bacterial load in the canals.

The authors wish to acknowledge the support of Denfotex Light Systems for supplying the light delivery system and consumables and for financial support to carry out the microbiological analyses.

1. Ruddle C J. Cleaning and shaping of the Root Canal System. In Cohen S, Burns R C (Ed). Pathways of the pulp. $8^{\text {th }}$ ed. pp 231-292. St Louis, Missouri: Mosby, 2002.

2. Sjögren U, Figdor D, Persson S, Sundqvist G. Influence of infection at the time of root filling on the outcome of endodontic treatment of teeth with apical periodontitis. Int Endod J 1997: 30: 297-306.

3. Sundqvist G, Figdor D, Persson S, Sjögren U. Microbiologic analysis of teeth with failed endodontic treatment and the outcome of conservative treatment. Oral Surg Oral Med Oral Pathol Oral Radiol Endod 1998; 85: 86-93.

4. Hancock H H III, Sigurdsson A, Trope M, Moiseiwitsch J. Bacteria isolated after unsuccessful endodontic treatment in a North American population. Oral Surg Oral Med Oral Pathol Oral Radiol Endod 2001: 91: 579-586.

5. Brannstrom M. Smear layer:pathological and treatment considerations. Oper Dent Supp/ 1984; 3: 35-48.

6. Olgart L Brannstrom M Johnson G. Invasion of bacteria into dentinal tubules. Experiments in vitro and in vivo. Acta Odontol Scand 1974; 32: 61-68.

7. Byström $A$, Sundqvist $\mathrm{G}$. Bacteriological evaluation of the effect of $0.5 \% \mathrm{NaOCl}$ in endodontic therapy. Oral Surg Oral Med Oral Path 1983; 55: 307-312

8. Byström A, Sundqvist $G$. The antibacterial action of sodium hypochlorite in 60 cases of endodontic therapy. Int Endod J 1985; 18: 35-40.

9. Ørstavik D, Haapsalo M. Disinfection by endodontic irrigants and dressings of experimentally infected dentinal tubules. Endod Dent Traumatol 1990; 6: 142-149.

10. Ohara $P$, Torabinejd $M$, Kettering J D. Antibacterial effects of various endodontic irrigants on selected anaerobic bacteria. Endod Dent Traumato/ 1993: 9: 95-100.

11. Siqueira J F, Batista M M D, Fraga R C, de Uzeda M. Antibacterial effects of endodontic irrigants on black-pigmented gram-negative anaerobes and facultative bacteria. J Endod 1998; 24: 414-416.

12. Siqueira J F, Rocas I N, Favieri A, Lima K C. Chemomechanical reduction of the bacterial population in the root canal after instrumentation and irrigation with $1 \%$ 2.5\% and 5.25\% sodium hypochlorite. J Endod 2000; 26: 331-334.

13. Ruddle C J. Cleaning and shaping of the Root Canal System. In Cohen S, Burns R C (Ed). Pathways of the pulp. $8^{\text {th }}$ ed. pp 231-292. St Louis, Missouri: Mosby, 2002

14. Radcliffe C E, Potouridou L, Quersgi $R$ et al. Antimicrobial activity of varying concentration of sodium hypochlorite on the endodontic microorganisms Actinomyces israelii, A naeslundi, Candida albicans and Enterococcus faecalis. Int Endodont J 2004; 37: 438-446.

15. Spangberg $L$, Langeland K. Biological effect of dental materials 1. Toxicity of root canal filling materials on HeLa cells in vitro. Oral Surgery Oral Med Oral Pathol 1973; 35: 402-414.

16. Spangberg $L$, Rutberg $M$, Rydinge E. Biological effects of antimicrobial agents. JEndodontics 1979; 5: 166-175.

17. Yesilsoy $C$, Whitaker $E, C l e v e l a n d D$ et al. Antimicrobial and toxic effects of established and potential root canal irrigants. J Endod 1995: 21:513-515.

18. Becker $G \mathrm{~L}$, Cohen $\mathrm{S}$, Borer $\mathrm{R}$. The sequaelae of accidentally irrigating sodium hypochlorite beyond the root apex. Oral Surg Oral Med Oral Pathol 1974; 38: 633-638.

19. Gemhardt $C R$, Eppendorf $K$, Kozlowski A, Brandt M. Toxicity of concentrated sodium hypochlorite on vital tissue. Int Endodont J 2004; 37: 272-280.

20. Ram Z. Effectiveness of root canal irrigation. Oral Surg Oral Med Oral Pathol 1977 44: 306-312

21. Slazgerber $R M$, Brilliant J D. An in vivo evaluation of the penetration of an irrigating solution in root canals. J Endod 1977; $\mathbf{3 : 3 9 4 - 3 9 8}$

22. Senia E S, Marshall F J, Rosen S. The solvent action of sodium hypochlorite on pulp tissue of extracted teeth. Oral Surg Oral Med Oral Pathol 1971; 31:96-103.

23. Bonsor S J, Nichol R, Reid T M S, Pearson G J. Microbiological evaluation of photoactivated disinfection in endodontics (An in vivo study.) Br DentJ (in press).

24. Williams J A, Pearson G J, Colles M J, Wilson M. The effect of variable energy input from a novel light source on the photoactivated bactericidal action of Toluidine Blue 0 on Streptococcus mutans. Caries Res 2003; 3: 190-192.

25. Williams J A, Pearson G J, Colles M J, Wilson M. The antibacterial effect of Toluidine Blue 0 on bacterial colonies in a collagen matrix and carious dentine. Caries Res 2004; 38: 530-536.

26. Williams J A, Colles M J, Pearson G J, Wilson M. Effectiveness of photo-activated disinfection against endodontic bacteria in planktonic suspension and in artificia and human root canals. J Dent (in press).

27. Bhatti $M$, MacRobert $A$, Henderson $B$, Wilson M. Exposure of Porphyromonas gingivalis to red light in the presence of the light-activated antimicrobial agent Toluidine Blue decreases the membrane fluidity. Current Microbio/2002; 45: 118-122.

28. O'Neil J F, Hope C K, Wilson M. Oral bacteria in multi-species biofilms can be killed by red light in the presence of Toluidine Blue. Lasers in Surgery and Medicine 2002 31: 86-90

29. Powis D R, Folleras T, Merson S A, Wilson A D. Improved adhesion of a glass ionomer cement to dentine and enamel. J Dent Res 1982; 61: 1416-1422.

30. Stringer G J, Bird P S, Walsh L J. Laser/dye killing of Streptococcus mutans in longitudinal and transverse dentine slices. J Dent Res 1999; 78: Sp edition 95 Abst.

31. Millson C E, Thurrell W, Buonaccorsi G et al. The effect of low power laser light at different doses on gastric mucosa sensitised with methylene blue, haematoporphyrin derivative or toluidine blue Lasers Med Sci 1997: 12: 145-150.

32. Komerik N, Curnow A, MacRobert A J et al. Fluorescence biodistribution and photosensitising activity of toluidene blue o on rat buccal mucosa. Lasers Med Sci 2002: 17: 96-92.

33. Egan J, Collis J, Pearson G J, Williams J. Transmission of $636 \mathrm{~nm}$ Diode laser light through dentine. Colorado, USA: Transaction of SPIE, 2000. 